\title{
Risk behaviours for HIV infection among injecting drug users attending a drug dependency clinic
}

\author{
G J Hart, C Sonnex, A Petherick, A M Johnson, C Feinmann, M W Adler
}

\begin{abstract}
To study a range of possible risk factors for HIV among injecting drug user patients attending a clinic in London were interviewed from November 1986 to November 1987. Serum samples were tested for viral markers. Of 116 patients, 101 had shared injecting equipment, 75 on the first occasion of injecting and 76 during the past year. Seventy said that sharing was because equipment was not available. In the past year 102 had been sexually active, a third having two to 20 partners; a quarter of the women had exchanged sexual intercourse for money. The four patients who were positive for antibody to HIV antigen had shared equipment or had intercourse with drug users from areas with a high prevalence of HIV. Eleven patients had injected drugs while in prison.

Despite a low prevalence of HIV infection this infection remains a threat to drug users in London; strenuous efforts are still needed to prevent its further transmission.
\end{abstract}

\section{Introduction}

In 1986 research from the United States' and Scotland ${ }^{2}$ indicated the potential for rapid spread of HIV infection among injecting drug users. Reports from London indicate a low prevalence of antibodies to HIV among injecting drug users, ${ }^{3}$ but data on risk behaviour are limited. ${ }^{4}$ We investigated a range of risk behaviours for HIV infection among drug users in London to identify means of preventing its further spread. We hoped also to understand further the epidemiology of HIV infection in a population of drug users in whom the prevalence of the disease was low. Too often the emphasis placed on a single activity-sharing needles and syringes-leads to the exclusion of other risk factors that may be important in the transmission of the virus among injecting drug users.

\section{Patients and methods}

The study was undertaken in conjunction with a health assessment service offered to patients entering treatment at a drug dependency clinic serving the north and centre of London. The service provided screening for infection with hepatitis B and skin and systemic disease and advice on contraception, pregnancy, and nutrition. Counselling and voluntary testing for HIV were an integral part of the service. Patients who agreed underwent a structured interview that lasted 20 minutes. We recorded demographic information, history of use of drugs and injecting behaviour, recent sexual behaviour and exposure to additional risk factors such as prostitution, and contact with drug users from areas with a high prevalence of HIV infection.
From November 1986 to November 1987, 116 consecutive injecting drug users attending the health assessment clinic were interviewed. Patients' names were not recorded, but each interview was allocated a coded number. Serum samples collected for clinical purposes were matched with the code number and stored; when the study was finished the code numbers were removed. At this stage of the analysis we could not relate serological results to individual patients. Samples were then tested blind for hepatitis B surface antigen, antibodies to hepatitis B core antigen, and antibodies to hepatitis B surface antigen by enzyme linked immunosorbent assay (ELISA). Antibody to HIV-I antigen was detected by competitive enzyme immunoassay (Wellcozyme); positive results were confirmed by antiglobulin ELISA (Abbott) and by a reverse antibody capture ELISA.

Base figures vary because some questions did not apply to patients or, occasionally, because of the need to shorten interviews to avoid detaining patients whose primary interest was to have their physical health assessed. Statistical analysis was undertaken with Pearson's correlation coefficient.

\section{Results}

Of the 116 drug users interviewed, 63 were men and 53 were women, a ratio of $1 \cdot 2: 1$. The mean age was 29 (range 19-47). All patients had injected drugs at some point in the past five years. The mean age at which they had begun injecting on a regular (that is, weekly) basis was 22; they had been injecting for a mean of seven years. Of 111 patients questioned, only six had not been introduced to injecting by another drug user; the rest had been helped to inject on the first occasion by friends (62), partners (25), acquaintances (13), or dealers (five). This was also the occasion when most had first shared needles and syringes: 75 patients had shared on the first occasion of injecting.

Patients were asked about their recent use of drugs. Eighty seven of 105 had primarily used heroin in the four weeks before entering the programme of treatment; other drugs used included methadone (six patients) and benzodiazepines (three). The favoured route of taking the drugs was injecting (77), followed by oral use (13), smoking (12), and sniffing (four). Drug use was frequent, with 96 using drugs daily.

Only 15 patients had never shared needles and syringes. Table I shows that of the 101 who had shared, most (56) had done so within the three months before entry to the treatment programme. We found that younger drug users, who had begun injecting after AIDS had first appeared, were more likely to have shared recently than older users, whose drug habits had been formed earlier $(p<0 \cdot 002)$. People with whom the patients shared injecting equipment were generally friends (51) or sexual partners (25), although 20 had shared with acquaintances or a dealer. We found no
Hart, academic department of genitourinary medicine. 
TABLE I-Recent behaviour concerning sharing needles and syringes among patients attending drug dependency clinic

No of patients

Last occasion of sharing $(n=101)$

Within week

1 Week to $<1$ month ago

1 Month to $<3$ months ago

3 to $<6$ Months ago

6 to $<12$ Months ago

1 to $<2$ Years ago

$\geqslant 2$ Years ago

Person(s) with whom shared $(n=96)$

Partner

Friend(s)

Acquaintance(s)

Dealer

evidence of injecting in so called "shooting galleries."

Table II gives the number of people with whom patients had shared within the year before the last occasion of sharing. Whereas 12 had not shared during this period, 36 had shared with between one and three people and 47 had shared with four or more; the mean was 4.5 (range 1-25). Of those questioned about their reasons for sharing ( 77 out of 101 ), 70 gave the scarcity or unavailability of needles and syringes at the time of injecting as their reason. In four instances it had occurred because a sexual partner had bought equipment for shared use, and in only three instances was sharing a long practised custom. Of 89 patients asked, 49 had used equipment supplied by a dealer.

Table III shows patients' sexual behaviour in the year before interview. None of the men but nine of the women had had more than 10 partners; these nine and a further four women (a quarter of all women questioned) had exchanged sexual intercourse for money within the past year. Of the 102 who had been sexually active, 46 had had partners who did not use drugs. Only six patients always used condoms with their regular sexual partners. Of the 52 who reported casual sexual partners in the previous year, 27 never used condoms and eight used them less than half of the time. Only 14 always used condoms with casual partners. All of the female prostitutes had used condoms when they received payment for intercourse but had not done so with their regular partner. Three male patients were bisexual; none was exclusively homosexual and none had exchanged intercourse for money.

Most patients were questioned about their use of drugs and sexual behaviour with drug users from Scotland and Ireland. All were asked about risk behaviours with drug users of other nationalities, and responses suggested that contact occurred most often with Italian drug users. Table IV shows that between five and 16 had shared needles with users from such high risk areas and between one and 19 had had sexual contact with injecting drug users from these areas.

Finally, all patients were asked about their possible exposure to infection in prison. Thirty two patients had spent some time in prison within the five years before the interview, of whom 18 had used drugs while in custody, mainly heroin (16/18); injecting was the favoured route of administration (11/18). Eight had shared equipment with other prisoners.

Patients were asked whether they had made any changes in their use of drugs and their sexual behaviour since AIDS had been identified. Fifty six of 90 patients had made changes in their use of drugs, of whom 17 were now not sharing equipment, 14 were sharing less, eight were not injecting, and six were injecting less. Only 28 patients, however, had made changes in their sexual behaviour. Of these, 13 were using condoms and eight had restricted sexual activity to one partner.

Table $\mathrm{V}$ gives the results of tests for viral markers and shows the low prevalence of antibody to HIV antigen in the study population (4/108). There was, however, a high prevalence of antibody to hepatitis B core antigens with 70 out of 110 patients carrying this marker of infection with hepatitis B. Those who had injected for less than five years were significantly less likely $(p<0.003)$ to have contracted hepatitis B than those who had injected for five years or more.

TABLE V-Viral markers present in serum samples collected from patients attending a drug dependency clinic

\begin{tabular}{lcc}
\hline Viral marker & $\begin{array}{c}\text { No who were } \\
\text { tested }\end{array}$ & $\begin{array}{c}\text { No who were } \\
\text { positive }\end{array}$ \\
\hline Antibody to HIV-I antigen & 108 & 4 \\
Antibody to hepatitis B surface antigen & 110 & 44 \\
Antibody to hepatitis B core antigen & 110 & 70 \\
Hepatitis B surface antigen & 110 & 4
\end{tabular}

\section{Discussion}

Recent studies of risk behaviour for HIV infection among people who inject drugs in Edinburgh ${ }^{5}$ and London $^{67}$ have focused on sharing needles and syringes. These studies have not reported extensively on other primary and secondary risk behaviours, notably sexual activity and contact with drug users from areas with a high prevalence of HIV infection or in other settings, such as prison. By providing a health assessment we were able to explore the broader context of risk.

Possibly patients attending this clinic for health assessment showed a concern for their health that is not present in other populations of drug users. Power et al in their comparison of an "agency group" (recruited in part from a drug dependency unit and some general practices) and a group not in contact with drug agencies found a significantly lower prevalence of risk related to injecting in the agency group. ' This suggests that our report on patients drawn from a drug dependency unit underestimates the prevalence of risk behaviours among drug users in London as a whole.

Reports from America maintain that there is a culture of sharing injecting equipment among users of intravenous drugs and that this occurs for social reasons. ${ }^{89}$ Neither we nor other workers (R Power, personal communication) found evidence supporting such community use. "Shooting galleries" were also not in evidence, unlike in Scotland, where they have arisen because of the unavailability of needles and syringes. ${ }^{10} \mathrm{We}$ therefore cannot assert, as have Ghodse et al, ${ }^{6}$ that sharing in this country is associated with a feeling of community. When asked why sharing had taken place 70 patients said that it was because of the scarcity or immediate unavailability of needles and syringes; none spoke of any community feeling engendered.

The past year has seen the increased availability of needles and syringes for drug users. At the time this study was done, however, increased access to injecting equipment through pharmacies and schemes for exchanging needles had just begun; recent changes in availability would therefore have had little effect on sharing of needles within our study population. Seventy six of those who had shared had done so within the year before interview, often with friends and acquaintances and occasionally with dealers. Use of equipment supplied by a dealer can also be considered a risk behaviour as there can be no certainty of its sterility.

Sexual activity in this population was interesting. One third of those interviewed had multiple sexual partners; six women who had received payment for intercourse reported more than 150 partners in the past year. Female prostitution was more common among
Glasgow $\quad 12 / 112 \quad 1 / 113$

Dundee $\quad 5 / 112 \quad 1 / 113$

$\begin{array}{lll}\text { Italy } & 16 / 116 & 19 / 116\end{array}$

$\begin{array}{lrr}\text { Other } & 8 / 116 & 10 / 116\end{array}$ 
our patients than among clients of needle exchange schemes $^{11}$ (25\% v 5\%), though condoms were reportedly always used with paying sexual partners. Consistent use of condoms with casual partners among all our sexually active patients was also more common $(27 \% v$ $7 \%$ ). Nevertheless, the amount of unprotected sexual activity is worrying, both for injecting drug users and their partners who do not use drugs ${ }^{12}$; 46 interviewees had partners who did not use drugs in the year before interview. There remains considerable scope for reducing sexual risks among injecting drug users and their partners.

Our finding that up to $16 \%(19 / 116)$ of the total sample had either shared equipment or had had intercourse with drug users from areas with a high prevalence of HIV shows the potential for viral spread as a result of the geographic mobility of users. ${ }^{13}$ Indeed, analysis of risk factors in the four cases of HIV infection that we identified suggested that additional factors, such as sharing with drug users from Edinburgh or Dublin, were relevant in explaining infection.

Recent concern about the spread of HIV infection within the prison system ${ }^{14}$ is was supported by our finding that $9 \%$ (11) of our total population had injected drugs while in prison in recent years, and most of these had shared equipment with other prisoners. Although $78 \%$ (90) of our sample were unemployed, $27 \%$ (31) were spending $\$ 500-2000$ a week on their drug habit, which suggests that some may have been breaking the law and risking imprisonment. Drugs, but few needles and syringes, are known to be smuggled into prison ${ }^{16}$ and so sharing needles is the inevitable result in the absence of programmes for treating drug users in prison.

Both in the United Kingdom ${ }^{5-7}$ and in the United States $^{1}$ evidence exists that drug users can adopt strategies to avoid risks related to their use of drugs and HIV. Our finding that $69 \%$ (62) of our population had made no change in their sexual behaviour (as opposed to $62 \%$ (56) reporting changes in use of drugs) should encourage workers to educate users about safer sex and to facilitate this through access to condoms.

Hepatitis B infection was endemic in our population, but older, long term injectors were more likely to have been infected than those who had started injecting more recently. Indeed, exposure to or concern about this infection may have influenced recent injecting behaviour; older users were less likely to have shared needles and syringes recently than young users. This suggests that the greatest risks of bloodborne viral infections are being run by young people who have recently started injecting. With two thirds of injecting drug users sharing equipment on the first occasion of injecting preventive programmes, particularly health outreach work, should be targeted at this high risk population.
Finally, the low prevalence of antibodies to HIV antigen in this population (4\%) could prove temporary in the light of the data presented. Studies in other populations of drug users have shown that once introduced the virus can spread rapidly if risk behaviours are sustained. ${ }^{17}{ }^{18}$ Our study population was fairly well motivated, and though we found no evidence of "community" drug use or shooting galleries, risk behaviours were still identified; there is probably a higher prevalence of activity related to risk among drug users who are not in contact with drug agencies. HIV infection remains a considerable threat, and though exchange of needles ${ }^{19}$ and increased provision of services ${ }^{20}$ and health outreach work ${ }^{21}$ all show potential for success in reducing its further spread, strenuous efforts are still needed if it is to be controlled properly within and beyond the drug using population.

We acknowledge financial support from the Medical Research Council for CS, AP, and AMJ and thank Peter Williams for data handling and statistical help.

1 Des Jarlais DC, Friedman SR. HIV infection among intravenous drug users: epidemiology and risk reduction. AIDS 1987;1:67-76.

2 Robertson JR, Bucknall ABV, Welsby PD, et al. Epidemic of AIDS related virus (HTLV-III/LAV) infection among intravenous drug abusers. Br Med 1986;292:527-9.

3 Webb G, Wells B, Morgan JR, McManus TH. Epidemic of AIDS related virus infection among intravenous drug abusers. $\mathrm{Br} M e d \mathcal{F} 1986 ; 292: 1202$.

4 Mulleady G, Green J. Syringe sharing among London drug abusers. Lancet 1985;ii: 1425 .

5 Robertson JR, Skidmore CA, Roberts JJK. HIV infection in intravenous drug users: a follow-up study indicating changes in risk-taking behaviour. Br $\mathcal{F}$ Addict 1988;82:387-91.

6 Ghodse AH, Tregenza G, Li M. Effect of AIDS on sharing of injection equipment among drug abusers. Br Med J 1986;292:698-9.

7 Power R, Hartnoll R, Daviaud E. Drug injection, AIDS and risk behaviour: potential for change and intervention strategies. Br $\mathcal{F}$ Addict 1988;83:649-54.

Howard J, Borges P. Needlesharing in the Haight: some social and psychological functions. I Health Soc Behav 1970;11:220-30.

9 Des Jarlais DC, Friedman SR, Strug D. AIDS and needle sharing within the Des Jarlais DC, Friedman SR, Strug D. AIDS and needle sharing within the
IV-drug subculture. In: Feldman DA, Johnson TM, eds. The social

dimensions of AIDS. New York: Praeger, 1986.
10 Scottish Home and Health Department. HIV infection in Scolland. Edinburgh: SHHD, 1986

11 Stimson GV, Alldritt L, Dolan K, Donoghoe M. Injecting equipment exchange schemes: a preliminary report on research. London: Goldsmith's College, 1988. 12 Moss AR. AIDS and intravenous drug use; the real heterosexual epidemit. BrMed f 1987;294:389-90.

13 Brettle RP, Bisset K, Burns S, et al. Human immunodeficiency virus and drug misuse: the Edinburgh experience. Br Med $\mathcal{F}$ 1987;295:421-4.

14 Prison Reform Trust. HIV, AIDS and prisons. London: Prison Reform Trust, 1988.

5 McMillan A. HIV in prisons. BrMed f 1988;297:873-4.

16 Vernon G, ed. Drug users and the prison system. London: Health Information Trust, 1987 .

17 Rodrigo JM, Serra MA, Aguila E, el al. HTLV-III antibodies in drug addicts in Spain. Lancet 1985;ii:156-7.

18 Angarano G, Pastore G, Monno L, et al. Rapid spread of HTLV-III infection among drug addicts in Italy. Lancet 1985; ii: 1302.

19 Stimson GV, Alldritt L, Dolan K, Donoghoe M. Syringe exchange schemes for drug users in England and Scotland. Br Med $\mathcal{F}$ 1988;296:1717-9.

20 Strang J. Changing injecting practices: blunting the needle habit. $B r \mathcal{F}$ Addict 1988;83:237-9.

21 Hart G. HIV and the injecting drug user. In: Aggleton P, Hart G, Davies P, eds. AIDS: social representations, social practices. Basingstoke: Falmer, 1989.

(Accepted 16 fanuary 1989)

\section{ANY QUESTIONS} Does the use of non-steroidal anti-inflammatory drugs interfere with the
antithrombotic action of low dose aspirin?

Aspirin exerts its antithrombotic effect by inhibiting the enzyme cyclooxygenase in platelets and thus the production of thromboxane $\mathrm{A}_{2}$, which produces platelet aggregation. It also inhibits vascular endothelial cyclo-oxygenase and thus the production of prostacyclin, which has antiaggregatory properties. Appreciable inhibition of thromboxane $A_{2}$ production occurs at lower doses of aspirin than those required to inhibit prostacyclin production, and it has been suggested that the effect on prostacyclin production of high doses of aspirin might counteract the antithrombotic effect. There is, however, no good evidence that this is of any clinical importance.

Non-steroidal anti-inflammatory drugs also inhibit cyclo-oxygenase in both platelets and vascular endothelium. The clinical importance of this is, however, unknown. Therapeutic doses of most non-steroidal antiinflammatory drugs inhibit platelet aggregation both in vitro and in vivo. There is in vitro evidence that therapeutic doses inhibit prostacyclin production, but whether this results in any proaggregatory effect in vivo is largely unknown. Therapeutic doses of ibuprofen seem to inhibit platelet aggregation without inhibiting prostacyclin release,' but I am not aware of any similar studies with other non-steroidal anti-inflammatory drugs.

It is theoretically possible that some non-steroidal anti-inflammatory drugs inhibit prostacyclin production to an extent that might counteract the antithrombotic effect of low dose aspirin, but I do not know of any studies that have looked at this.-LINDA BEELEY, director, drug and therapeutics unit, Birmingham

1 Longnecker GL, Swift A, Bowen RJ, Beyers BJ, Shah AK. Kinetics of ibuprofen effects on platelet and endothelial prostanoid release. Clin Pharmacol Ther 1985;37:343-8. 